\title{
Is Your Sales Manager Attractive? Examining the Impact of Attractiveness on Credibility: An Abstract
}

\author{
Edward Nowlin, Doug Walker, Nawar Chaker, and Nwamaka A. Anaza
}

\begin{abstract}
The credibility of a sales manager in the eyes of the salesperson is a key component of leadership effectiveness (Bass and Bass 2009; Bettinghaus and Baseheart 1969; Malshe 2010). The authors describe how salespeople form judgements about their managers' credibility based on an emotional connection driven by their managers' physical features (Busenitz e al. 2005; Lord et al. 1984). A salesperson will have a higher level of affective commitment to a more attractive manager, resulting in a perception that the manager is more credible. Consistent with signaling theory and implicit leadership theories, attractiveness signals a halo effect that the manager is able, up-to-date, and competent. The halo affect manifests itself as affective commitment. The ability to process these signals and use them to make assessments increases with experience. Therefore, manager attractiveness will have a greater effect on perceived manager credibility for experienced salespeople than for inexperienced salespeople.
\end{abstract}

\footnotetext{
E. Nowlin $(\bowtie) \cdot$ D. Walker

Kansas State University, Manhattan, KS, USA

e-mail: elnowlin@ksu.edu; dmwalker@ksu.edu

N. Chaker

Elon University, Elon, NC, USA

e-mail: nchaker@elon.edu

\section{N. A. Anaza}

Southern Illinois University Carbondale, Carbondale, IL, USA

e-mail: nanaza@siu.edu
} 